OPEN ACCESS

Edited by: Marianna Bei,

Harvard Medical School, USA

Reviewed by: Henrique De Amorim Almeida, Polytechnic Institute of Leiria, Portugal Miguel Angel Mateos Timoneda, Institute for Bioengineering of Catalonia, Spain

*Correspondence: Stanley Chung

chung.st@husky.neu.edu

Thomas J. Webster

th.webster@neu.edu

Specialty section: This article was submitted to Clinical and Translational Physiology, a section of the journal Frontiers in Physiology

Received: 26 April 2016 Accepted: 28 June 2016 Published: 14 July 2016

Citation:

Chung S, Ercan B, Roy AK and Webster TJ (2016) Addition of Selenium Nanoparticles to Electrospun Silk Scaffold Improves the Mammalian Cell Activity While Reducing Bacterial Growth.

Front. Physiol. 7:297.

doi: 10.3389/fphys.2016.00297

\section{Addition of Selenium Nanoparticles to Electrospun Silk Scaffold Improves the Mammalian Cell Activity While Reducing Bacterial Growth}

\author{
Stanley Chung ${ }^{1 *}$, Batur Ercan ${ }^{1}$, Amit K. Roy ${ }^{1,2}$ and Thomas J. Webster 1, 2, 3,4* \\ ${ }^{1}$ Department of Chemical Engineering, Northeastern University, Boston, MA, USA, ${ }^{2}$ Wenzhou Institute of Biomaterials and \\ Engineering, Wenzhou Medical University, Wenzhou, China, ${ }^{3}$ Center of Excellence for Advanced Materials Research, King \\ Abdulaziz University, Jeddah, Saudi Arabia, ${ }^{4}$ Department of Bioengineering, Northeastern University, Boston, MA, USA
}

Silk possesses many beneficial wound healing properties, and electrospun scaffolds are especially applicable for skin applications, due to their smaller interstices and higher surface areas. However, purified silk promotes microbial growth. Selenium nanoparticles have shown excellent antibacterial properties and are a novel antimicrobial chemistry. Here, electrospun silk scaffolds were doped with selenium nanoparticles to impart antibacterial properties to the silk scaffolds. Results showed significantly improved bacterial inhibition and mild improvement in human dermal fibroblast metabolic activity. These results suggest that the addition of selenium nanoparticles to electrospun silk is a promising approach to improve wound healing with reduced infection, without relying on antibiotics.

Keywords: silk, electrospinning, antibacterial nanoparticles

\section{INTRODUCTION}

Researchers in the tissue engineering field work toward repairing and/or regenerating damaged tissues and organs through a combination of biomaterial scaffolds, cell signaling moieties, and cell (Langer and Vacanti, 1993). The ideal tissue engineering scaffold closely mimics the physical and chemical makeup of the organ to be replaced and should serve as an artificial extracellular matrix to support cell growth and differentiation. Electrospun scaffolds closely mimic the physical composition of native extracellular matrix (ECM) morphology.

Electrospinning works by applying a high voltage field to a solution of polymer dissolved in a conductive solvent (Sill and von Recum, 2008). The voltage induces electrostatic repulsion within the polymer solution and forms a cone like structure, the Taylor cone, held together by the force balance of the electrostatic repulsion and surface tension. Eventually, the electrostatic repulsion overcomes the surface tension forces holding the polymer solution together. Once this critical limit has been reached, a polymer jet is formed out of the edge of the Taylor cone toward a positively charged collector, and the solvent is evaporated in the flight path from the cone to the collector, leaving a polymer matrix with fibers relevant to physiological regime. The physical parameters of the scaffold may be adjusted based on polymer composition, solvent mixture, voltage, and many other parameters used to create the matrix. Researchers also have a high degree of control over the fiber orientation of electrospun scaffolds by adjusting the type of collector. Because of these processing advantages, electrospinning has been researched for a variety of tissue engineering applications 
such as cardio (Hajiali et al., 2011; Liu et al., 2011; Du et al., 2012), bone (Shin et al., 2010; Cai et al., 2012; Frohbergh et al., 2012; Liu et al., 2014), neural (Wang et al., 2011; Guan et al., 2013; Kador et al., 2013; Prabhakaran et al., 2013; Baiguera et al., 2014; Irani et al., 2014), skin (Dhandayuthapani et al., 2010; Jin et al., 2011; Kuppan et al., 2011; Rnjak-Kovacina et al., 2011), tendon/ligament (Howell et al., 2004; Sahoo et al., 2010a,b; James et al., 2011; Cardwell et al., 2012), and stem cell expansion/differentiation (Shin et al., 2010; Sahoo et al., 2010a; James et al., 2011; Jin et al., 2011; Wang et al., 2011; Cardwell et al., 2012; Irani et al., 2014).

Electrospun scaffolds promote many beneficial cellular responses for tissue engineering and are generally better for cell proliferation and differentiation than $2 \mathrm{D}$ substrates. In particular, silk electrospun scaffolds demonstrate good responses as tissue engineering scaffold for wound healing (Wharram et al., 2010; Gil et al., 2013; Lee et al., 2014). Silk promotes collagen synthesis, re-epithelialization, wound healing, atopic dermatitis alleviation, and scar reduction (Ricci et al., 2004; Fini et al., 2005; Roh et al., 2006; Okabayashi et al., 2009). However, pure silk shows negligible or even negative antibacterial properties (Kaur et al., 2014). Previously, groups have loaded electrospun silk scaffold with silver nanoparticles to impart anti-bacterial properties (Kang et al., 2007). However, silver is a commonly used antibiotic that has become resistant in certain strains of bacteria (Silver, 2003).

Selenium nanoparticles are a novel antibiotic chemistry to which there is no known bacterial resistance (Tran and Webster, 2011, 2013; Wang and Webster, 2012, 2013; Shakibaie et al., 2015). Selenium is a common trace element in the body and is important to healthy nutrition, especially in the formation of selenoproteins (Andrews et al., 2011; Santhosh Kumar and Priyadarsini, 2014). Selenium has been suggested to have anticancer effects as well (Clark et al., 1996). Here, we doped selenium nanoparticles to electrospun silk scaffold to impart antibacterial properties to silk (Rockwood et al., 2011). Human dermal fibroblasts were used to determine the in vitro changes in metabolic activity while Staphylococcus aureus were used to determine the effects of the bacterial inhibition.

\section{MATERIALS AND METHODS}

\section{Materials}

Bombyx mori silk cocoons were obtained from Mulberry Farms (Fallbrook, CA). Formic acid was purchased from Sigma-Aldrich (Saint Louis, MO). Selenium nanoparticles were synthesized as described below.

\section{Extraction of Silk Fibroin from Bombyx Mori Silk Cocoons}

Silk fibroin was prepared from Bombyx mori cocoons according to previously established protocols with minor modifications (Rockwood et al., 2011). B. mori silk cocoons were cut into small pieces and boiled in $0.02 \mathrm{M} \mathrm{Na}_{2} \mathrm{CO}_{3}$ (Sigma-Aldrich) for $30 \mathrm{~min}$ to remove the glue-like sericin coating layer from the structural fibroin protein which was then rinsed $3 \mathrm{x}$ with distilled water $\left(\mathrm{diH}_{2} \mathrm{O}\right)$. The obtained silk fibroin fibers were dried overnight, dissolved in a $\mathrm{LiBr}$ (Sigma-Aldrich) solution $(9.3 \mathrm{M})$ at $60^{\circ} \mathrm{C}$ for $4 \mathrm{~h}$, and dialyzed through a cellulose membrane (ThermoFisher, Waltham, MA, 3500, MWCO) across distilled water for 4 days. The obtained silk solutions were centrifuged thrice at $4200 \mathrm{~g}$ and lyophilized for 4 days before resuspending in formic acid for a final concentration of $8 \%$ silk/formic acid.

\section{Electrospinning of Silk/Formic Acid Solution}

Eight percentage of silk solution was then electrospun at 18,000 volts, room temperature, $0 \%$ relative humidity, and $60 \mathrm{~cm}$ to collector. These conditions were optimized to produce fibers with dimensions that resemble those from the native extracellular matrix. Afterwards, 70\% methanol (Sigma-Aldrich) was used to treat the electrospun silk to prevent hydrolysis of the membrane. Treated silk membranes were dried overnight in the fume hood.

\section{Selenium Nanoparticle Synthesis}

$0.1 \mathrm{M}$ sodium selenite [Alfa Aesar, Ward Hill, MA, $\mathrm{Na}_{2} \mathrm{SeO}_{3}\left(\mathrm{H}_{2} \mathrm{O}\right)_{5}$ ] and $0.1 \mathrm{M}$ glutathione, GSH (Alfa Aesar), $\left(\mathrm{C}_{10} \mathrm{H}_{17} \mathrm{~N}_{3} \mathrm{O}_{6} \mathrm{~S}\right)$ were added onto the treated membranes before $0.2 \mathrm{M}$ sodium hydroxide $(\mathrm{NaOH})$ was added to precipate the sodium nanoparticles. Finally, double distilled deionized water was added thrice to quench the reaction and wash the membranes.

\section{Specimen Characterization}

Imaging of the specimens was conducted with a Hitachi S4800 Tokyo, Japan Scanning Electron Microscope (SEM, Hitachi S4800 SEM, Tokyo, Japan). A $4.5 \mathrm{~nm}$ layer of platinum was sputter coated (Cressington 208; Cressington Scientific Instruments, Watford, UK) onto the membranes to provide a conductive surface. SEM analysis was conducted with a $3 \mathrm{kV}$ accelerating voltage. Characterization was completed using both secondary electrons and backscatter electrons, which impart a stronger signal to heavier elements, such as selenium.

\section{Cellular Assays}

Mammalian Cell Activity Culture and Characterization Passages 3-12 human dermal fibroblast (HDF, Lonza, Basel, Switzerland) were cultured in Dulbecco's Modified Eagle Medium (DMEM, Sigma Aldrich) supplemented with $10 \%$ fetal bovine serum (Hyclone, Logan, UT) and $1 \%$ penicillin/streptomycin (P/S, Sigma Aldrich) in a $37^{\circ} \mathrm{C}$, humidified, $5 \% \mathrm{CO}_{2} / 95 \%$ air environment.

MTS assay (Promega, Fitchburg, WI) was used to determine the metabolic cell activity of the HDFs. Before cell seeding, the electrospun silk scaffolds were washed with $70 \%$ ethanol (Sigma-Aldrich) before rinsing with double distilled deionized water. HDFs were cultured to $\sim 90 \%$ confluence, rinsed with Dulbecco's phosphate-buffered saline without calcium chloride and magnesium chloride (dPBS, Sigma Aldrich), and detached from the tissue culture plate by using $0.25 \%$ trypsin-EDTA (Sigma-Aldrich). Detached cells were then centrifuged at 2000 r.p.m. and resuspended at a density of 50,000 cells $/ \mathrm{ml}$ before seeding onto the silk scaffolds in a 96 well-plate at $100 \mu \mathrm{l}$ in each well (5000 cells/well). The HDFs incubated for 1 , 2, and 4 days. Afterwards, the medium was removed from the sample and 
$100 \mu \mathrm{l}$ solution of 1:5 MTS dye with DMEM medium (v/v) were added to each well. Samples were placed back into the incubator for $2.5 \mathrm{~h}$. to allow the MTS to react with the metabolic products of the adherent cells before reading in a SpectraMax M3 microplate reader (Molecular Devices, Sunnyvale, CA) at an absorbance wavelength of $490 \mathrm{~nm}$. The absorbance values of wells containing only DMEM medium without cells were subtracted from the absorbance values of the wells containing cells. The metabolic activity of each well was compared with the metabolic activity of known numbers of cells by a standard curve constructed at the beginning of each trial.

\section{Bacterial Cell Activity Measurement}

Staphylococcus aureus (ATCC-12600) were inoculated in 3\% tryptic soy broth (TSB, Sigma-Aldrich) overnight. After 24 h., the Staphylococcus aureus were diluted with TSB until absorbance value reached 0.52 at wavelength of $562 \mathrm{~nm}$. This corresponded with a cell density of $10^{9}$ colony forming units (CFU)/ml. Afterwards, the Staphylococcus aureus were diluted 1000x in TSB before seeding onto the silk samples in a non-treated 96 well-plate in $100 \mu \mathrm{l}$ of solution $\left(10^{5} \mathrm{CFU} /\right.$ well). After 24 h., the BacTiter Glo assay (Promega), a luciferase based ATP assay was used to quantify the amount of ATP present on the electrospun silk samples. BacTiter Glo reagent was added at the same volume as the medium in each well, $100 \mu \mathrm{l}$, at room temperature. The samples were inoculated at room temperature for $5 \mathrm{~min}$. while the BacTiter Glo reagents solubilized the bacterial membrane, after which, the luminescence was measured using the SpectraMax M3. A standard curve was constructed to equate the luminescence readings with known ATP amounts.

\section{Statistics}

All experiments were conducted in triplicate and repeated at least three times each. Analysis of variance and student's $t$-test were used to determine whether the differences in cellular activity over the different time periods were significant.

\section{RESULTS AND DISCUSSION}

To characterize the morphology of the electrospun silk scaffold, scanning electron microscope was used to visualize the surface of the nanocomposite. As shown in Figures 1A,B, the electrospun silk scaffolds contained fiber diameters $\sim 100-200 \mathrm{~nm}$ and pore sizes $\sim 2 \mu \mathrm{m}$. The silk scaffold contained unaligned fibers with very little beading and uniform thickness, demonstrating a morphology similar to those in the native extra-cellular matrix (ECM). The selenium nanoparticles (SeNP) were then reacted on the scaffold, causing a physisorption of the SeNP onto the silk scaffold. Two reaction conditions were chosen to deposit the SeNPs; SEM images showed that these produced two homogenous and distinct selenium nanoparticle populations: 40 (Figures 1C,D) and $70 \mathrm{~nm}$ (Figures 1E,F) nanoparticles.

First, in vitro viability tests were conducted using HDF cells. These cells were seeded onto the silk scaffold without selenium nanoparticles, the silk scaffolds containing the 40 and $70 \mathrm{~nm}$ selenium nanoparticles, and on regular polystyrene (PS) tissue culture plate to determine the change in growth of the HDF cells when grown on these substrates (Figure 2). Electrospun silk without addition of selenium nanoparticles produced statistically insignificant change $(p>0.05)$ in HDF activity as compared

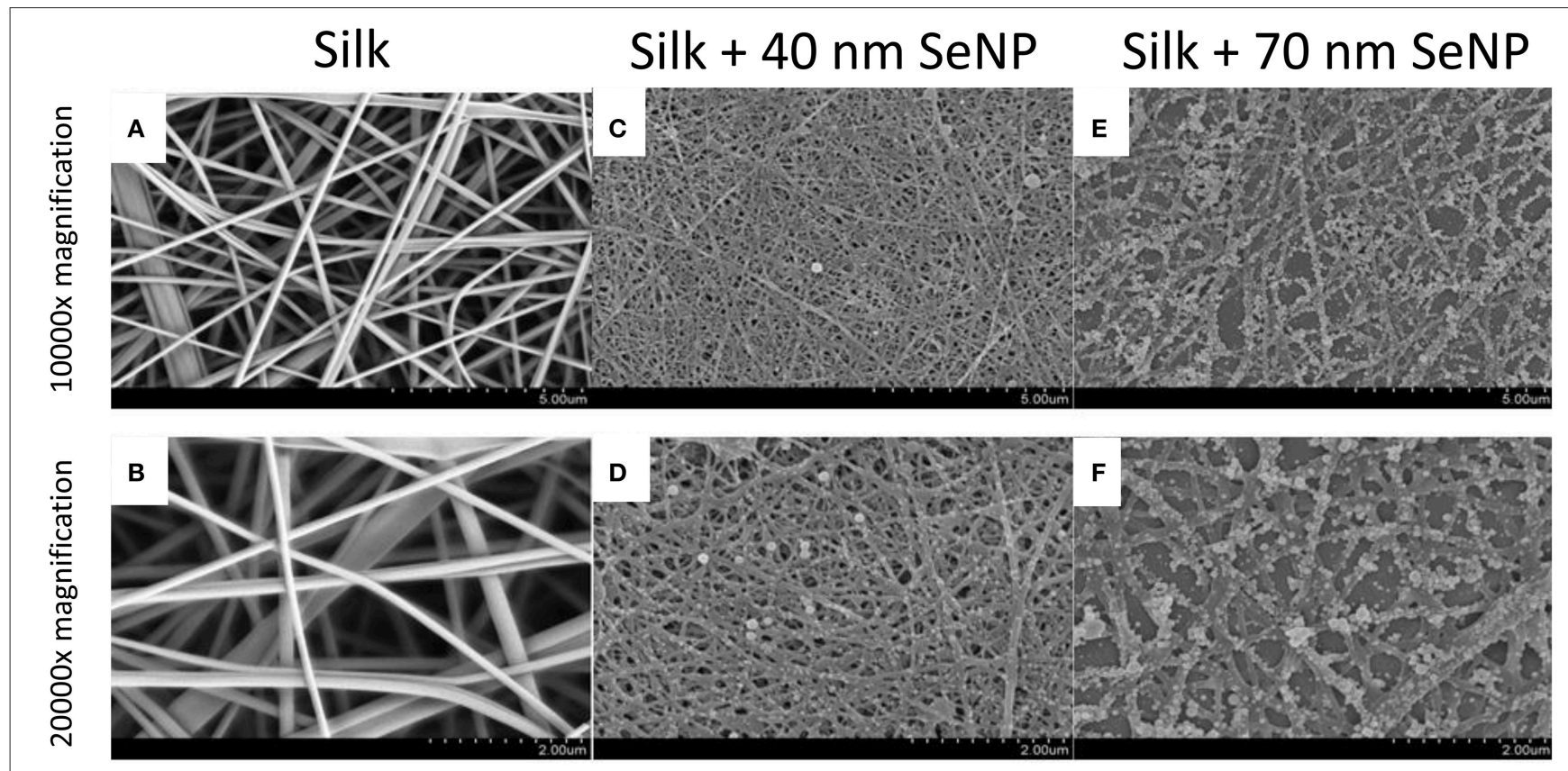

FIGURE 1 | Scanning electron microscopy (SEM) images of the electrospun silk scaffolds at 10,000x (A,C,E) and 20,000x (B,D,F) with 5 and $2 \mu \mathrm{m}$ scale bars respectively. The silk scaffolds without selenium nanoparticles are shown in panels (A,B); with $40 \mathrm{~nm}$ selenium nanoparticle in panels (C,D); and with $70 \mathrm{~nm}$ selenium nanoparticles in panels (E,F). 

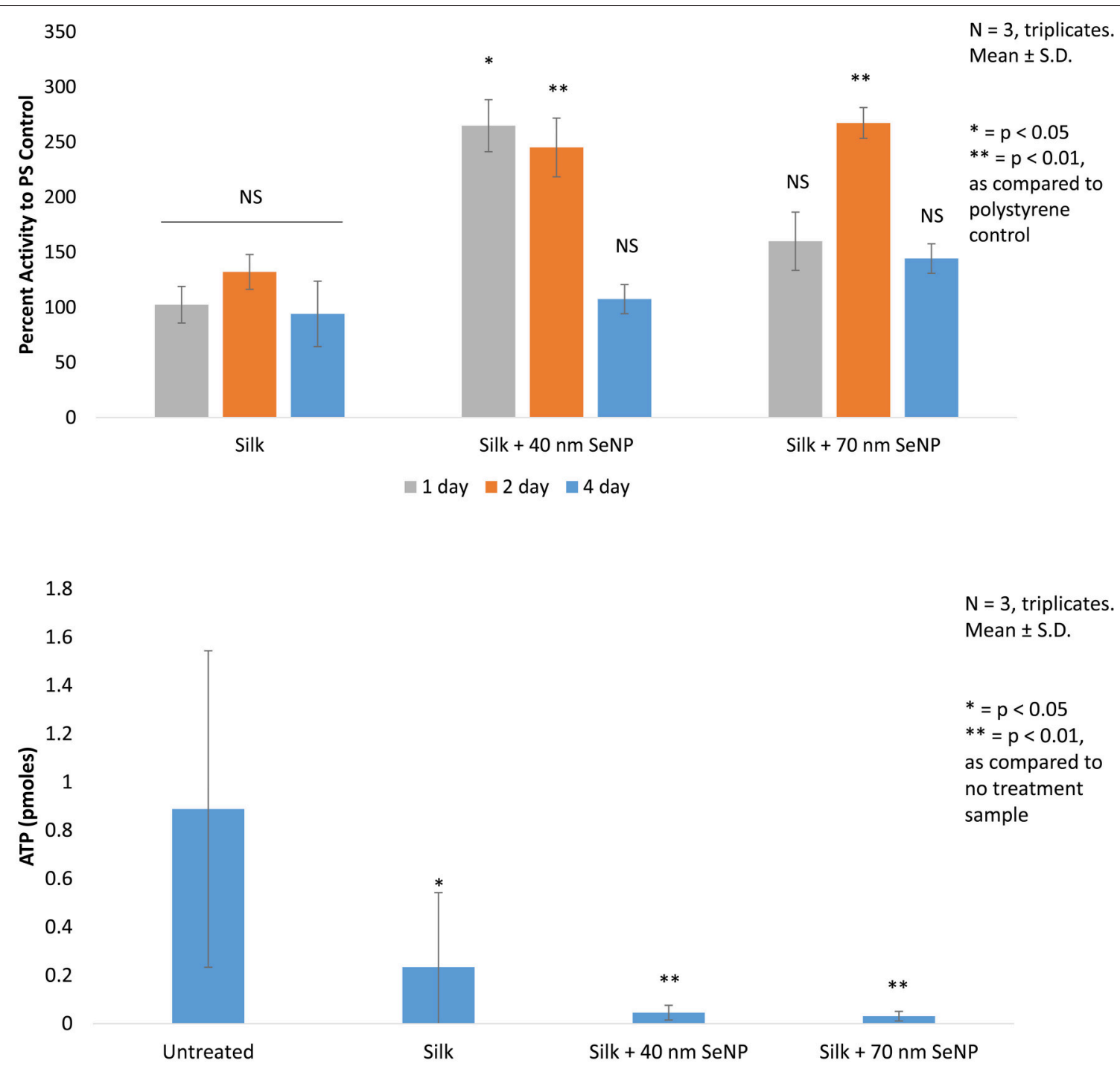

FIGURE 2 | In vitro cellular activity are depicted. (Top) The mitochondrial activity of human dermal fibroblast (HDF) grown on silk, silk +40 nm selenium nanoparticles, and silk $+70 \mathrm{~nm}$ selenium nanoparticles are compared to activity of HDF grown on polystyrene tissue culture dish. All trials are conducted in triplicates, $N=3 .{ }^{*} p<0.05,{ }^{*} p<0.01$ as compared to polystyrene control. (Bottom) The ATP activity of Staphylococcus aureus grown on the same sample groups as tested for the HDF is depicted. All trials are conducted in triplicates, $N=3 .{ }^{*} p<0.05,{ }^{\star *} p<0.01$ as compared to no treatment sample.

activity when grown on normal tissue culture plate across all 3 days tested. The silk/selenium nanocomposites produced significantly higher metabolic activity for HDF as compared to HDF grown on tissue culture plate. The addition of selenium nanoparticles significantly improved the metabolic activity of HDF, especially at the shorter term time points. At 1 and 2 days, silk scaffold doped with $40 \mathrm{~nm}$ selenium nanoparticles produced greater than two fold increase in metabolic signal, 264 and $245 \%$ on day 1 and 2, respectively, as compared to the tissue culture plate control while the $70 \mathrm{~nm}$ scaffold produced 160 and $267 \%$ on day 1 and 2 , respectively. The day $1(p<0.05)$ and day 2 signal $(p<0.01)$ from the silk $+40 \mathrm{~nm}$ SeNP scaffolds and the day 2 signal $(p<0.05)$ from the silk+70 nm SeNP scaffolds were statistically significant from the signal produced at the same time points on the tissue culture plates. Surprisingly, the silk scaffolds without nanoparticle addition did not produce a statistically significant improvement in HDF growth despite the ECM like morphology. There was mild improvement on day 2 (132\% compared to control), but overall, the presence of silk alone did not significant improve HDF response. The short term improvement in activity may have plateaued by day 4 compared to the control, because the HDF may have reached confluency on the silk/selenium nanocomposites.

Finally, the bacteria results were accessed by ATP assay. Here, the performance of the silk scaffolds were compared to Staphylococcus aureus grown in solution in the polystyrene plate. Bacterial growth across all silk samples showed statistically significant reduction as compared to untreated samples grown in 
solution. Bacteria grown on silk without selenium nanoparticles showed a $74 \%$ reduction as compared with the control $(p<0.05)$. This was somewhat surprising, because this contradicted other reports found in literature (Kaur et al., 2014).

Addition of selenium nanoparticles significantly improved the bacterial load: the addition of the $40 \mathrm{~nm}$ selenium nanoparticles reduced bacterial load by $95 \%$ and the $70 \mathrm{~nm}$ selenium nanoparticles by $96 \%$ compared to the control $(p<0.01)$. The doping of selenium had achieved an additional reduction of $80 \%$ for the $40 \mathrm{~nm}$ selenium nanoparticle and $87 \%$ for the $70 \mathrm{~nm}$ selenium nanoparticle as compared to the silk samples. The 70 $\mathrm{nm}$ selenium nanoparticle produced an almost one log reduction in ATP content (0.88) as compared to the silk sample and an overall $1.4 \log$ reduction compared to the control.

\section{CONCLUSION}

This study showed for the first time the efficacy of doping selenium nanoparticles with silk to improve bacterial efficacy. Reaction conditions successfully synthesized two different sized populations of selenium nanoparticles onto electrospun silk scaffolds. These nanocomposites were then compared to silk scaffolds and normal tissue culture plates and were found to significantly improve both the mammalian cell response while reducing bacterial cell activity. Addition of the selenium nanoparticles significantly improved the short term human dermal fibroblast metabolic activity while reducing the ATP content of Staphylococcus aureus. Together, these results suggest that selenium nanoparticle may selectively enhance

\section{REFERENCES}

Andrews, P. J. D., Avenell, A., Noble, D. W., Campbell, M. K., Croal, B. L., Simpson, W. G., et al. (2011). Randomised trial of glutamine, selenium, or both, to supplement parenteral nutrition for critically ill patients. BMJ 342:d1542. doi: 10.1136/bmj.d1542

Baiguera, S., Del Gaudio, C., Lucatelli, E., Kuevda, E., Boieri, M., Mazzanti, B., et al. (2014). Electrospun gelatin scaffolds incorporating rat decellularized brain extracellular matrix for neural tissue engineering. Biomaterials 35, 1205-1214. doi: 10.1016/j.biomaterials.2013.10.060

Cai, Y.-Z., Zhang, G.-R., Wang, L.-L., Jiang, Y.-Z., Ouyang, H.-W., and Zou, X.-H. (2012). Novel biodegradable three-dimensional macroporous scaffold using aligned electrospun nanofibrous yarns for bone tissue engineering. J. Biomed. Mater. Res. Part A. 100A, 1187-1194. doi: 10.1002/jbm.a.34063

Cardwell, R. D., Dahlgren, L. A., and Goldstein, A. S. (2012). Electrospun fibre diameter, not alignment, affects mesenchymal stem cell differentiation into the tendon/ligament lineage. J. Tissue Eng. Regen. Med. 8, 937-945. doi: 10.1002/term.1589

Clark, L. C., Combs, G. F. Jr., Turnbull, B. W., Slate, E. H., Chalker, D. K., Chow, J., et al. (1996). Effects of selenium supplementation for cancer prevention in patients with carcinoma of the skin: a randomized controlled trial. JAMA 276, 1957-1963. doi: 10.1001/jama.1996.03540240035027

Dhandayuthapani, B., Krishnan, U. M., and Sethuraman, S. (2010). Fabrication and characterization of chitosan-gelatin blend nanofibers for skin tissue engineering. J. Biomed. Mater. Res. Part B Appl. Biomater. 94B, 264-272. doi: 10.1002/jbm.b.31651

Du, F., Wang, H., Zhao, W., Li, D., Kong, D., Yang, J., et al. (2012). Gradient nanofibrous chitosan/poly $\varepsilon$-caprolactone scaffolds as extracellular microenvironments for vascular tissue engineering. Biomaterials 33, 762-770. doi: 10.1016/j.biomaterials.2011.10.037 mammalian cells functions while killing or reducing the bacterial load. In summary, this study provides evidence of the potential value of the use of selenium nanoparticles in skin applications due to their selective activity. Future works will focus on determining the mechanism by which selenium nanoparticles achieve this selectivity and the scope of the selenium nanoparticles for inhibiting bacteria in skin applications.

\section{AUTHOR CONTRIBUTIONS}

SC and BE made substantial contributions to conception and design, and acquisition of data, and nanalysis and interpretation of data. Equally contributed to planning and idea. AR participated in design of experiment/idea and revising the article. TW edited/revised it critically for important intellectual content and gave final approval of the version to be submitted and any revised version.

\section{FUNDING}

The authors would like to thank Northeastern University for funding and facilities.

\section{ACKNOWLEDGMENTS}

The authors thank Mr. William H. Fowle (Northeastern University) for help with the SEM and the Nanomedicine Laboratory.

Fini, M., Motta, A., Torricelli, P., Giavaresi, G., Nicoli Aldini, N., Tschon, M., et al. (2005). The healing of confined critical size cancellous defects in the presence of silk fibroin hydrogel. Biomaterials 26, 3527-3536. doi: 10.1016/j.biomaterials.2004.09.040

Frohbergh, M. E., Katsman, A., Botta, G. P., Lazarovici, P., Schauer, C. L., Wegst, U. G., et al. (2012). Electrospun hydroxyapatite-containing chitosan nanofibers crosslinked with genipin for bone tissue engineering. Biomaterials 33, 9167-9178. doi: 10.1016/j.biomaterials.2012.09.009

Gil, E. S., Panilaitis, B., Bellas, E., and Kaplan, D. L. (2013). Functionalized silk biomaterials for wound healing. Adv. Healthc. Mater. 2, 206-217. doi: 10.1002/adhm.201200192

Guan, S., Zhang, X.-L., Lin, X.-M., Liu, T.-Q., Ma, X.-H., and Cui, Z.-F. (2013). Chitosan/gelatin porous scaffolds containing hyaluronic acid and heparan sulfate for neural tissue engineering. J. Biomater. Sci. 24, 999-1014. doi: 10.1080/09205063.2012.731374

Hajiali, H., Shahgasempour, S., Naimi-Jamal, M. R., and Peirovi, H. (2011) Electrospun PGA/gelatin nanofibrous scaffolds and their potential application in vascular tissue engineering. Int. J. Nanomed. 6, 2133-2141. doi: 10.2147/IJN.S24312

Howell, M. D., Jones, J. F., Kisich, K. O., Streib, J. E., Gallo, R. L., and Leung, D. Y. M. (2004). Selective killing of vaccinia virus by LL-37: implications for eczema vaccinatum. J. Immunol. 172, 1763-1767. doi: 10.4049/jimmunol.172.3.1763

Irani, S., Zandi, M., Salamian, N., Saeed, S. M., Daliri Joupari, M., and Atyabi, S. M. (2014). The study of P19 stem cell behavior on aligned oriented electrospun poly(lactic-co-glycolic acid) nano-fibers for neural tissue engineering. Polym. Adv. Technol. 25, 562-567. doi: 10.1002/pat.3280

James, R., Kumbar, S. G., Laurencin, C. T., Balian, G., and Chhabra, A. B. (2011) Tendon tissue engineering: adipose-derived stem cell and GDF-5 mediated regeneration using electrospun matrix systems. Biomed. Mater. 6:25011. doi: $10.1088 / 1748-6041 / 6 / 2 / 025011$ 
Jin, G., Prabhakaran, M. P., and Ramakrishna, S. (2011). Stem cell differentiation to epidermal lineages on electrospun nanofibrous substrates for skin tissue engineering. Acta Biomater. 7, 3113-3122. doi: 10.1016/j.actbio.2011.04.017

Kador, K. E., Montero, R. B., Venugopalan, P., Hertz, J., Zindell, A. N., Valenzuela, D. A., et al. (2013). Tissue engineering the retinal ganglion cell nerve fiber layer. Biomaterials 34, 4242-4250. doi: 10.1016/j.biomaterials.2013.02.027

Kang, M., Jung, R., Kim, H.-S., Youk, J. H., and Jin, H.-J. (2007). Silver nanoparticles incorporated electrospun silk fibers. J. Nanosci. Nanotechnol. 7, 3888-3891. doi: 10.1166/jnn.2007.056

Kaur, J., Rajkhowa, R., Afrin, T., Tsuzuki, T., and Wang, X. (2014). Facts and myths of antibacterial properties of silk. Biopolymers 101, 237-245. doi: 10.1002/bip. 22323

Kuppan, P., Vasanthan, K. S., Sundaramurthi, D., Krishnan, U. M., and Sethuraman, S. (2011). Development of Poly(3-hydroxybutyrate-co-3hydroxyvalerate) fibers for skin tissue engineering: effects of topography, mechanical, and chemical stimuli. Biomacromolecules 12, 3156-3165. doi: 10.1021/bm200618w

Langer, R., and Vacanti, J. P. (1993). Tissue engineering. Science 260, 920-926. doi: $10.1126 /$ science. 8493529

Lee, O. J., Ju, H. W., Kim, J. H., Lee, J. M., Ki, C. S., Kim, J. H., et al. (2014). Development of artificial dermis using 3D electrospun silk fibroin nanofiber matrix. J. Biomed. Nanotechnol. 10, 1294-1303. doi: 10.1166/jbn.2014.1818

Liu, H., Li, X., Zhou, G., Fan, H., and Fan, Y. (2011). Electrospun sulfated silk fibroin nanofibrous scaffolds for vascular tissue engineering. Biomaterials 32, 3784-3793. doi: 10.1016/j.biomaterials.2011.02.002

Liu, Y., Cui, H., Zhuang, X., Wei, Y., and Chen, X. (2014). Electrospinning of aniline pentamer-graft-gelatin/PLLA nanofibers for bone tissue engineering. Acta Biomater. 10, 5074-5080. doi: 10.1016/j.actbio.2014.08.036

Okabayashi, R., Nakamura, M., Okabayashi, T., Tanaka, Y., Nagai, A., and Yamashita, K. (2009). Efficacy of polarized hydroxyapatite and silk fibroin composite dressing gel on epidermal recovery from full-thickness skin wounds. J. Biomed. Mater. Res. Part B Appl. Biomater. 90B, 641-646. doi: 10.1002/jbm.b.31329

Prabhakaran, M. P., Vatankhah, E., and Ramakrishna, S. (2013). Electrospun aligned PHBV/collagen nanofibers as substrates for nerve tissue engineering. Biotechnol. Bioeng. 110, 2775-2784. doi: 10.1002/bit.24937

Ricci, G., Patrizi, A., Bendandi, B., Menna, G., Varotti, E., and Masi, M. (2004). Clinical effectiveness of a silk fabric in the treatment of atopic dermatitis. $\mathrm{Br}$. J. Dermatol. 150, 127-131. doi: 10.1111/j.1365-2133.2004.05705.x

Rnjak-Kovacina, J., Wise, S. G., Li, Z., Maitz, P. K. M., Young, C. J., Wang, Y., et al. (2011). Tailoring the porosity and pore size of electrospun synthetic human elastin scaffolds for dermal tissue engineering. Biomaterials 32, 6729-6736. doi: 10.1016/j.biomaterials.2011.05.065

Rockwood, D. N., Preda, R. C., Yucel, T., Wang, X., Lovett, M. L., and Kaplan, D. L. (2011). Materials fabrication from Bombyx mori silk fibroin. Nat. Protocols 6, 1612-1631. doi: 10.1038/nprot.2011.379

Roh, D.-H., Kang, S.-Y., Kim, J.-Y., Kwon, Y.-B., Young Kweon, H., Lee, K. G., et al. (2006). Wound healing effect of silk fibroin/alginate-blended sponge in full thickness skin defect of rat. J. Mater. Sci. Mater. Med. 17, 547-552. doi: 10.1007/s10856-006-8938-y

Sahoo, S., Ang, L. T., Goh, J. C.-H., and Toh, S.-L. (2010b). Growth factor delivery through electrospun nanofibers in scaffolds for tissue engineering applications. J. Biomed. Mater. Res. Part A. 93A, 1539-1550. doi: 10.1002/jbm.a.32645
Sahoo, S., Toh, S. L., and Goh, J. C. H. (2010a). A bFGF-releasing silk/PLGA-based biohybrid scaffold for ligament/tendon tissue engineering using mesenchymal progenitor cells. Biomaterials 31, 2990-2998. doi: 10.1016/j.biomaterials.2010.01.004

Santhosh Kumar, B., and Priyadarsini, K. I. (2014). Selenium nutrition: how important is it? Biomed. Preventive Nutr. 4, 333-341. doi: 10.1016/j.bionut.2014.01.006

Shakibaie, M., Forootanfar, H., Golkari, Y., Mohammadi-Khorsand, T., and Shakibaie, M. R. (2015). Anti-biofilm activity of biogenic selenium nanoparticles and selenium dioxide against clinical isolates of Staphylococcus aureus, Pseudomonas aeruginosa, and Proteus mirabilis. J. Trace Elements Med. Biol. 29, 235-241. doi: 10.1016/j.jtemb.2014. 07.020

Shin, M., Yoshimoto, H., and Vacanti, J. P. (2010). "In vivo bone tissue engineering using mesenchymal stem cells on a novel electrospun nanofibrous scaffold," in Advances in Tissue Engineering, Vol. 2, eds P. C. Johnson and A. G. Mikos (Mary Ann Liebert), 205-213.

Sill, T. J., and von Recum, H. A. (2008). Electrospinning: applications in drug delivery and tissue engineering. Biomaterials 29, 1989-2006. doi: 10.1016/j.biomaterials.2008.01.011

Silver, S. (2003). Bacterial silver resistance: molecular biology and uses and misuses of silver compounds. FEMS Microbiol. Rev. 27, 341-353.

Tran, P. A., and Webster, T. J. (2011). Selenium nanoparticles inhibit Staphylococcus aureus growth. Int. J. Nanomedicine. 6:1553. doi: 10.2147/IJN.S21729

Tran, P. A., and Webster, T. J. (2013). Antimicrobial selenium nanoparticle coatings on polymeric medical devices. Nanotechnology 24, 155101. doi: 10.1088/0957-4484/24/15/155101

Wang, A., Tang, Z., Park, I.-H., Zhu, Y., Patel, S., Daley, G. Q., et al. (2011). Induced pluripotent stem cells for neural tissue engineering. Biomaterials 32, 5023-5032. doi: 10.1016/j.biomaterials.2011.03.070

Wang, Q., and Webster, T. J. (2012). Nanostructured selenium for preventing biofilm formation on polycarbonate medical devices. J. Biomed. Mater. Res. Part A 100A, 3205-3210. doi: 10.1002/jbm.a. 34262

Wang, Q., and Webster, T. J. (2013). Short communication: inhibiting biofilm formation on paper towels through the use of selenium nanoparticles coatings. Int. J. Nanomed. 8:407. doi: 10.2147/IJN.S38777

Wharram, S. E., Zhang, X., Kaplan, D. L., and McCarthy, S. P. (2010). Electrospun silk material systems for wound healing. Macromol. Biosci. 10, 246-257. doi: 10.1002/mabi.200900274

Conflict of Interest Statement: The authors declare that the research was conducted in the absence of any commercial or financial relationships that could be construed as a potential conflict of interest.

Copyright (c) 2016 Chung, Ercan, Roy and Webster. This is an open-access article distributed under the terms of the Creative Commons Attribution License (CC $B Y)$. The use, distribution or reproduction in other forums is permitted, provided the original author(s) or licensor are credited and that the original publication in this journal is cited, in accordance with accepted academic practice. No use, distribution or reproduction is permitted which does not comply with these terms. 